\title{
«Concurrency» in M-L-Parallel Semi-Markov Process
}

\author{
Eugene Larkin ${ }^{1}$ and Alexey Ivutin ${ }^{2}$ \\ ${ }^{1}$ Tula State University, Department of Robotics and Industry Mechanization, 300012, Tula, Russia \\ ${ }^{2}$ Tula State University, Department of Computer Technology, 30012, Tula, Russia
}

\begin{abstract}
This article investigates the functioning of a swarm of robots, each of which receives instructions from the external human operator and autonomously executes them. An abstract model of functioning of a robot, a group of robots and multiple groups of robots was obtained using the notion of semi-Markov process. The concepts of aggregated initial and aggregated absorbing states were introduced. Correspondences for calculation of time parameters of concurrency were obtained.
\end{abstract}

\section{Introduction}

Mobile robots are widely applied for environmental monitoring in counterterrorism, ecology and intelligence systems and in systems for rectification of consequences of technological disasters, etc. Despite the differences among the multiple environments, in which the robot can operate (air, ground, above-water, underwater ones) and despite the differences in the performed functions, the robot as a controlled object, has typical structure comprised of a sensor subsystem, on-board control computer, actuating devices and mechanisms, as well as of means of communication with a remote control station. Computer-based control over the robotic units and mechanisms comes down to the performance of the sequence of actions that unfold in time. Each action can be characterized by a random time period, measured from the beginning of the action to its end, as well as by random transition to another action of the sequence, if there is an alternative of continuation.

Thus, semi-Markov process is an adequate model of control over the single robot, which is characterized by multiple states, random time of being in the states and the stochastic nature of transition into the conjugated state. In practice, the use of separate mobile robots is ineffective, so the group use of robots using the so-called swarm technologies is an actively developing field. In this regard, the development of new principles and approaches to the organization of control over the swarm, performing a common task, for example, the development of model control process, which is carried out with the temporary concurrence of the functioning and organization of several modeling circuits. A special case of such control is when the commands are given to the subgroup of robots, included into the group, and within the execution of external commands, each unit of the swarm retains its autonomy, which means that the commands are reduced to the realization of one of the cyclograms, that were programmed in the onboard computer during the design stage [2-5]. Actions and status of each of the robots in the group, unfold in time, and switching from the current state to one of the possible following states is random for the external observer. Therefore, the same mathematical apparatus of semi-Markov processes can be used to model the functioning of organized swarms of robots [6$10]$.

\section{ML-parallel semi-Markov}

To summarize the above said, it could be noted that in this section we will focus on the modeling of the socalled M-L-parallel semi-Markov processes, in which there are M-parallel processes divided into L groups.

Let us define the elementary semi-Markov process as

$$
\mu_{m}^{\prime}=\left\{A_{m}^{\prime}, \mathbf{r}_{m}^{\prime}, \mathbf{h}_{m}^{\prime}(t)\right\}
$$

where $A_{m}^{\prime}$ is a number of states, among which there is at least one initial and one absorbing state; $\mathbf{r}_{m}^{\prime}$ - adjacency matrix; $\mathbf{h}_{m}^{\prime}(t)$ - semi-Markov matrix; $1 \leq \mathrm{m} \leq \mathrm{M}$.

Using the methods described in $[4,6,9,10]$, the process (1) can be transformed into an elementary process including one initial and one absorbing state,

$$
\mu_{m}=\left\{A_{m}, \mathbf{r}_{m}, \mathbf{h}_{m}(t)\right\}
$$

where $A_{m}=\left\{a_{1(m)}, a_{2(m)}\right\} ; a_{1(m)}$ - the initial state; $a_{2(m)}$ absorbing state; $\mathbf{r}_{m}=\left[\begin{array}{ll}0 & 1 \\ 0 & 0\end{array}\right], \mathbf{h}_{m}(t)=\left[\begin{array}{cc}0 & f_{m}(t) \\ 0 & 0\end{array}\right]-$ the adjacency matrix and semi-Markov matrix respectively; $f_{m}(t)$ - distribution density of time of the process being in the state $a_{1(m)}$ until it switches to the state $a_{2(m)}$. 


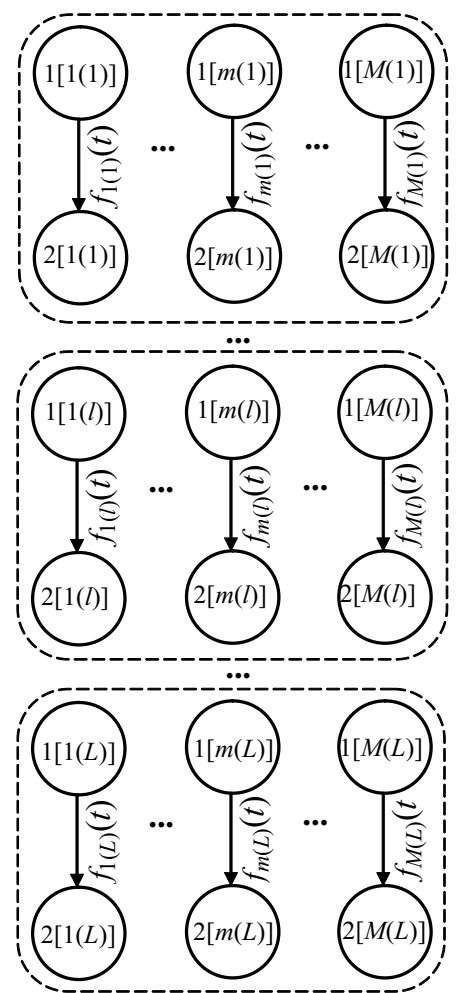

Figure 1. The structure of M-L-parallel semi-Markov process.

Processes (2) combine into L groups with M (1) elementary processes of type (2) in a group (Fig. 1). In the meantime $\sum_{l=1}^{L} M(l)=M, 1(l) \leq m(l) \leq M(l)$.

1 group of the semi-Markov processes can be represented as

$$
{ }^{l} \mu=\left\{{ }^{l} A,{ }^{l} \mathbf{r},{ }^{l} \mathbf{h}(t)\right\}
$$

where

$$
{ }^{l} A=\left\{\begin{array}{l}
\left.\left\{a_{1[1(l)]}, a_{2[1(l)]}\right\}, \ldots,\left\{a_{1[m(l)]}, a_{2[m(l)]}\right\}, \ldots,\right\} \\
\left\{a_{1[M(l)]}, a_{2[M(l)]}\right\}
\end{array}\right\}
$$

$$
{ }^{l} \mathbf{r}=\left[\begin{array}{cccccccc}
0 & 1 & & & & & & \\
0 & 0 & & & & & 0 & \\
& & \cdots & & & & & \\
& & & 0 & 1 & & & \\
& & & 0 & 0 & & & \\
& & & & & \cdots & & \\
& 0 & & & & & 0 & 1 \\
& & & & & & 0 & 0
\end{array}\right]
$$

$$
{ }^{l} \mathbf{h}(t)=\left[\begin{array}{cccccccc}
0 & f_{1(l)}(t) & & & & & & \\
0 & 0 & & & & & 0 \\
& & \cdots & & & & & \\
& & & 0 & f_{m(l)}(t) & & & \\
& & & 0 & 0 & & & \\
& & & & & \cdots & & \\
& 0 & & & & & 0 & f_{M(l)}(t) \\
& & & & & & 0 & 0
\end{array}\right]
$$
form:

M-L-parallel semi-Markov process has the following

$$
{ }^{M, L} \boldsymbol{\mu}=\left\{{ }^{M, L} A,{ }^{M, L} \mathbf{r},{ }^{M, L} \mathbf{h}(t)\right\}
$$

where

$$
{ }^{M, L} A=\bigcup_{l=1}^{L}{ }^{l} A
$$

It is believed that 1 group of semi-Markov processes reaches the aggregated absorbing state, when the last process in the group, for example, the $m(l)$, switches to the state $a_{2[m(l)]}$, and there are no other semi-Markov processes in the 1 group, which have not reached one of $\mathrm{M}(1)$ absorbing states. In this case, the group has a single absorbing state, which is the aggregated absorbing state of group.

We can assume without loss of generality that 1 group consists of elementary semi-Markov processes (2) with the numbers $\sum_{n=1}^{l-1} M(n)+1 \leq m(l) \leq \sum_{n=1}^{l} M(n)$, and thus the indices $m$ are recalculated according to the indices $m(l)$ using the correspondence:

$$
m=m(l)+\sum_{n=1}^{l-1} M(n)
$$

The distribution density of time taken by the 1 group of semi-Markov processes to reach the aggregated absorbing state is calculated with the correspondence [1113]

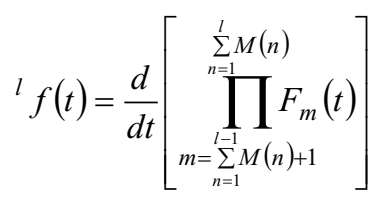

\section{The total semi-Markov process}

Correspondence (12) allows representing the $l$ group of semi-Markov processes as an aggregated semi-Markov process, which includes the aggregated initial state $a_{1(l)}=\bigcup_{m(l)=1(l)}^{M(l)} a_{1[m(l)]}$ and the aggregated absorbing state $a_{w(l)}=\bigcup_{m(l)=1(l)}^{M(l)} a_{2[m(l)]}$. Consequently, $M$ - L-parallel semiMarkov process can be represented as $L$-parallel semiMarkov process, which comprises $2 L$ states 
$\left\{a_{1(1)}, \ldots, a_{1(l)}, \ldots, a_{1(l)}, \quad a_{2(1)}, \ldots, a_{2(l)}, \ldots, a_{2(l)}\right\}$ and is described by semi-Markov matrix

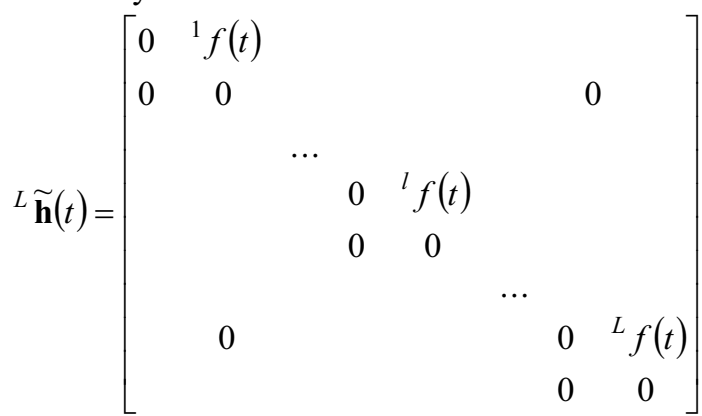

The distribution density of time taken by the $l$ group of semi-Markov processes to be the first to reach the aggregated absorbing state of the semi-Markov processes (before the other groups have reached their absorbing states) is calculated according to the correspondence

$$
{ }^{l} f_{w}(t)=\frac{{ }^{l} f(t) \cdot \prod_{\substack{n=1 \\ n \neq l}}^{L}\left[1-{ }^{n} F(t)\right]}{{ }^{l} p_{w}}
$$

where ${ }^{l} p_{w}$ - the probability that the $l$ group of semiMarkov processes the first one out of $L$-parallel processes to reach the aggregated absorbing state:

$$
{ }^{l} p_{w}=\int_{0}^{\infty} f(t) \cdot \prod_{\substack{n=1 \\ n \neq l}}^{L}\left[1-{ }^{n} F(t)\right] d t
$$

Numerical characteristics of the distribution density (14) are calculated, according to the correspondences

$$
\begin{gathered}
{ }^{l} T_{w}=\int_{0}^{\infty} t \frac{{ }^{l} f(t) \cdot \prod_{\substack{n=1 \\
n \neq l}}^{L}\left[1-{ }^{n} F(t)\right]}{{ }^{l} p_{w}} d t \\
{ }^{l} D_{w}=\int_{0}^{l} f(t) \cdot \prod_{\substack{n=1 \\
n \neq l}}^{L}\left[1-{ }^{n} F(t)\right] \\
\left.{ }^{l} p_{w} T_{w}\right)^{2}
\end{gathered}
$$

The distribution density of time the aggregated absorption state is reached by the last $l$ group of semiMarkov processes (after the other groups have reached their absorbing states) is calculated by the correspondence

$$
{ }^{l} f_{\bar{w}}(t)=\frac{{ }^{l} f(t) \cdot \prod_{\substack{n=1 \\ n \neq l}}^{L}{ }^{n} F(t)}{{ }^{l} p_{\bar{w}}}
$$

where ${ }^{l} p_{\bar{w}}$ - the probability that the $l$ group of semiMarkov processes will be the last one out of $L$-parallel processes to reach the aggregated absorbing state:

$$
{ }^{l} p_{\bar{w}}=\int_{0}^{\infty} l f(t) \cdot \prod_{\substack{n=1 \\ n \neq l}}^{L}{ }^{n} F(t) d t
$$

Numerical characteristics of the distribution density (17) are calculated by correspondences:

$$
\begin{gathered}
{ }^{l} T_{\bar{w}}=\int_{0}^{\infty} t \frac{{ }^{l} f(t) \cdot \prod_{\substack{n=1 \\
n \neq l}}^{L}{ }^{n} F(t)}{{ }^{l} p_{\bar{w}}} d t \\
{ }^{l} D_{\bar{w}}=\int_{0}^{\infty}\left(t-{ }^{l} T_{\bar{w}}\right)^{2} \frac{{ }_{\substack{n=1 \\
n \neq l}}^{L}{ }^{n} F(t)}{{ }^{l} p_{\bar{w}}} d t, 1 \leq l \leq L .
\end{gathered}
$$

The latency period for the $l$ group of semi-Markov processes, which has already reached the aggregated absorbing state, before $k$ group reaches its aggregated absorbing state, is defined as:

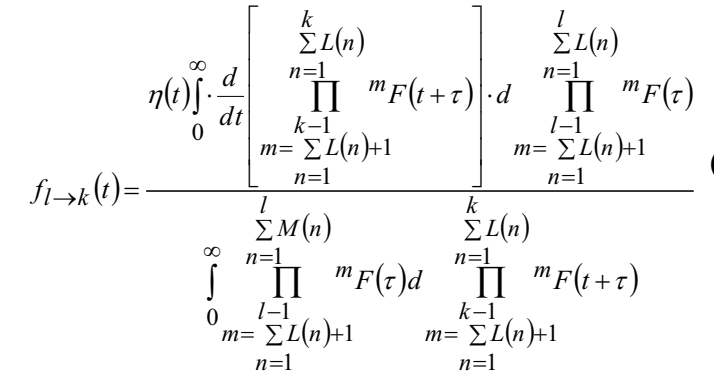

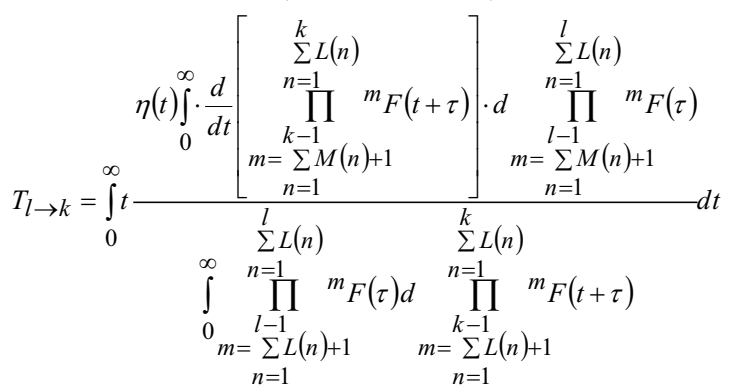

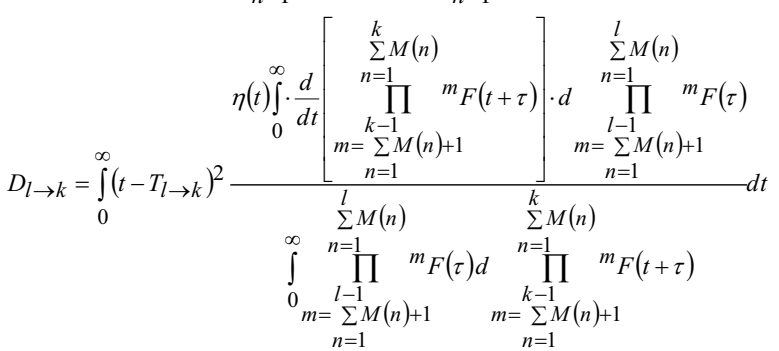

\section{Reaching of the aggregated absorbing states by any $K$ out of $L$ groups of parallel processes}

In case when the fact of reaching of aggregated absorbing states by any $K$ of $L, K<L$, groups of parallel processes, is of primary importance, the density of time distribution of the specified event is calculated by the correspondence

$$
f_{M L}^{K}(t)=\frac{d \sum_{c_{L}^{K}=1}^{C_{L}^{K}} \prod_{l=1}^{L} \Phi\left({ }^{l} f, \sigma_{l}^{c_{L}^{K}}\right)}{d t}
$$


where ${ }^{l} f(t)$ - the distribution density of time spent by the $l$ group of semi-Markov processes to reach the aggregated absorbing state, calculated by the correspondence (12); $c_{L}^{K}$ - the number of the figure in the range $N_{L}^{K}=\left\{n_{1}, \ldots, n_{c_{L}^{K}}, \ldots, n_{C_{L}^{K}}\right\} ; C_{L}^{K}-K$ binomial coefficient raised to the power of $L ; n_{c_{L}^{K}}=\left\langle\sigma_{1}^{c_{L}^{K}}, \ldots, \sigma_{l}^{c_{L}^{K}}, \ldots, \sigma_{L}^{c_{L}^{K}}\right\rangle$ the figure from the range $N_{L}^{K} ; \sigma_{l}^{c_{L}^{K}}-l$ digit place of $n_{c_{L}^{K}}$, which can take two values in accordance with (3.29); $C_{L}^{K}=\frac{L !}{K \cdot(L-K) !} ; \Phi\left({ }^{l} f, \sigma_{l}^{c_{L}^{K}}\right)$ - function that can get values

$$
\Phi\left({ }^{l} f, \sigma_{l}^{c_{L}{ }^{K}}\right)=\left\{\begin{array}{l}
{ }^{l} F(t), \text { if } \sigma_{l}^{c_{L}{ }^{k}}=1 ; \\
{\left[1-F_{l}(t)\right], \text { if } \sigma_{l}^{c_{L}{ }^{K}}=0}
\end{array}\right.
$$

For the distribution density (23) numeric characteristics can be found:

$$
\begin{gathered}
T_{M L}^{K}=\int_{0}^{\infty} t \cdot d \sum_{c_{L}^{K}=1}^{C_{L}^{K}} \prod_{l=1}^{L} \Phi\left({ }^{l} f, \sigma_{l}^{c_{L}^{K}}\right) \\
D_{M L}^{K}=\int_{0}^{\infty}\left(t-T_{L}^{K}\right)^{2} d \sum_{c_{L}^{K}=1}^{C_{L}^{K}} \prod_{l=1}^{M} \Phi\left({ }^{l} f, \sigma_{l}^{c_{L}^{K}}\right)
\end{gathered}
$$

To determine the cost of a losing (winning) the "concurrency" it is necessary to use the procedures set forth in [11-13]. In this case, the cost of waiting should be calculated for the case when one group of semiMarkov processes is waiting for all the semi-Markov processes of another group to reach the aggregated absorbing state.

\section{Conclusion}

Thus, the model of functioning of a swarm of robots, in the form of $M L$-parallel semi-Markov process has been developed. The correspondences, determining the time intervals of switching from the current aggregated state to the conjugated aggregated states have been obtained, which makes it possible to estimate the time of the performance of a command given to a swarm of robots, with calculation accuracy of distribution density. Further research is associated with the development of simple engineering techniques for synthesis of optimal algorithms to control a swarm, basing on the theoretical assumptions and using win/loss cost in case of uncoordinated actions of separate robots of the swarm as the major criterion for optimization.

Benefit of proposed technology of modeling of swarm is that the operability and an effectiveness of a soft under development may be evaluated on the stage of design without costly experiments on real swarm.

The reported study was partially supported by RFBR and Tula Region Government, research project No. 1641-710160 r_a.

\section{References}

1. Ivutin A.N., Larkin E.V., Kotov V.V. Established Routine of Swarm Monitoring Systems Functioning // Advances in Swarm and Computational Intelligence. Lecture Notes in Computer Science. Springer International Publishing, Switzerland, (2015) - Vol. 9141 - pp. 415-422. DOI: 10.1007/978-3-319-20472-7_45.

2. Ivutin A.N., Larkin E.V. Generalized Semi-Markov Model of the Algorithm for Digital Devices' Control // Izvestiya of Tula State University. Ser. Technical science. Vol. 1. Tula: Tula State University Publishing House, (2013). pp. 221-228.

3. Larkin E.V., Ivutin A.N. Estimation of Latency in Embedded Real-Time Systems // 3-rd Mediterranean Conference on Embedded Computing (MECO-2014). 2014. June 15-19. Budva, Montenegro, (2014). Pp. 236-239.

4. Larkin E.V., Ivutin A.N. Calculation of Time in the Control Algorithms // Izvestiya of Tomsk Polytechnic University. No. 5. Vol. 324. (2014). pp. 6-12.

5. Klintsov G.N., Larkin E.V. Control of Tunnel-boring Systems Using SCADA Software // Izvestiya of Tula State University. Ser. Technical science. Vol. 9. Part 1. Tula: Tula State University Publishing House, (2014). pp. 156-162.

6. Ivutin A.N., Larkin E.V. Time and Probability Characteristics of Transactions in Digital Control Systems // Izvestiya of Tula State University. Ser. Technical science. Vol. 1. - Tula: Tula State University Publishing House, (2013). pp. 252-258.

7. Ivutin A.N., Larkin E.V. Predicting the Runtime of the Algorithm // Izvestiya of Tula State University. Technical science. Vol. 3. - Tula: Tula State University Publishing House, (2013). pp. 301-315.

8. Larkin E.V., Kotov V.V., Kotova N.A. Evaluating the Efficiency of Robot's Software Using PetriMarkov net // Izvestiya of Tula State University. Technical science. Vol. 9. Part 2. - Tula: Tula State University Publishing House, (2013). pp. 156-163.

9. Klintsov G.N., Larkin E.V. Semi-Markov Modeling of Application Perfomance Algorhythms for Computer // Izvestiya of Tula State University. Ser. Technical science. Vol. 9. Part 1. (2015). pp. 143149.

10. Larkin E.V., Privalov A.N., Klepikov A.K. Algorithm of Sequential Simplifications in Evaluation of Time Complexity of Algorithms with Semi-Markov Models // Izvestiya of Tula State University. Ser. Technical science. Vol. 9. Part 2. Tula: Tula State University Publishing House, (2014). pp. 83-98.

11. Larkin E.V., Lutskov Yu.I., Ivutin A.N., Novikov A.S. Simulation of concurrent process with PetriMarkov nets // Life Science Journal. (2014). N. 11. pp. 506-511. (ISSN: 1097-8135). http.lifesciencesite.com.

12. Ivutin A.N, Larkin E.V. Simulation of Concurrent Games // Bulletin of the South Ural State University. Series: Mathematical Modeling, Programming and 
Computer Software. Chelyabinsk. 2015. Vol. 8. No. 2. pp. 43-54. DOI: 10.14529/mmp150204

13. Ivutin A.N, Larkin E.V. Simulation of Concurrent Games // Bulletin of the South Ural State University. Series: Mathematical Modeling, Programming and Computer Software. - Chelyabinsk, 2015. - Vol. 8, no. 2. pp. 43-54. DOI: $10.14529 / \mathrm{mmp} 150204$ 